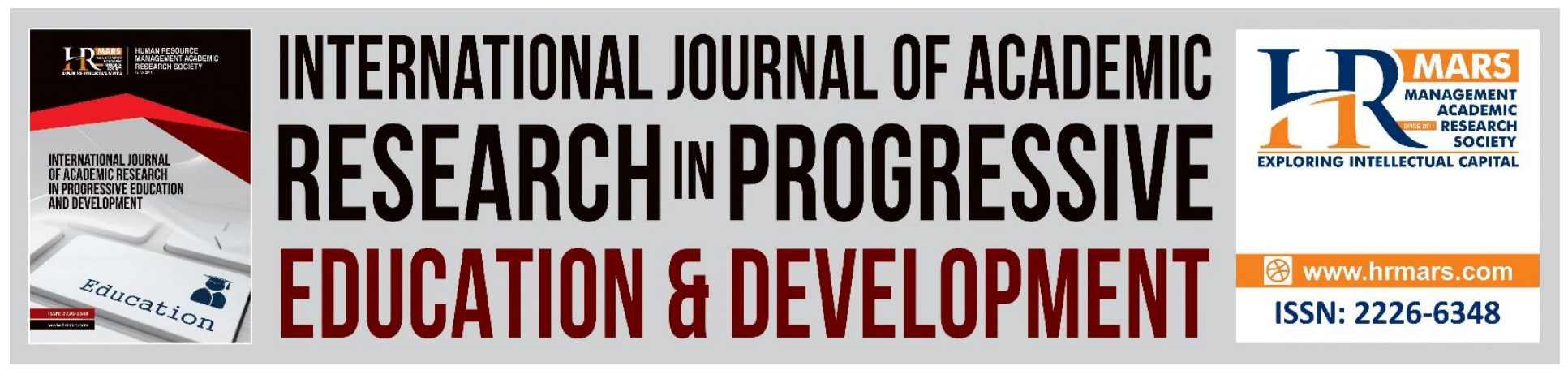

\title{
Big Data towards Decision-Making Culture in Organization
}

Saiful Farik Mat Yatin Ahmad Nasim Mohd Sidek, Hanis Zawani Mobidin, Siti Nurul Atiqah Adam

To Link this Article: http://dx.doi.org/10.6007/IJARPED/v7-i3/4351

DOI: $10.6007 /$ IJARPED/v7-i3/4351

Received: 03 June 2018, Revised: 11 June 2018, Accepted: 13 July 2018

Published Online: 29 July 2018

In-Text Citation: (Sidek, Mobidin, \& Adam, 2018)

To Cite this Article: Sidek, S. F. M. Y. A. N. M., Mobidin, H. Z., \& Adam, S. N. A. (2018). Big Data towards DecisionMaking Culture in Organization. International Journal of Academic Research in Progressive Education and Development, 7(3), 103-115.

\section{Copyright: (c) 2018 The Author(s)}

Published by Human Resource Management Academic Research Society (www.hrmars.com)

This article is published under the Creative Commons Attribution (CC BY 4.0) license. Anyone may reproduce, distribute, translate and create derivative works of this article (for both commercial and non-commercial purposes), subject to full attribution to the original publication and authors. The full terms of this license may be seen at: http://creativecommons.org/licences/by/4.0/legalcode

Vol. 7, No. 3, July 2018, Pg. 103 - 115

Full Terms \& Conditions of access and use can be found at http://hrmars.com/index.php/pages/detail/publication-ethics 


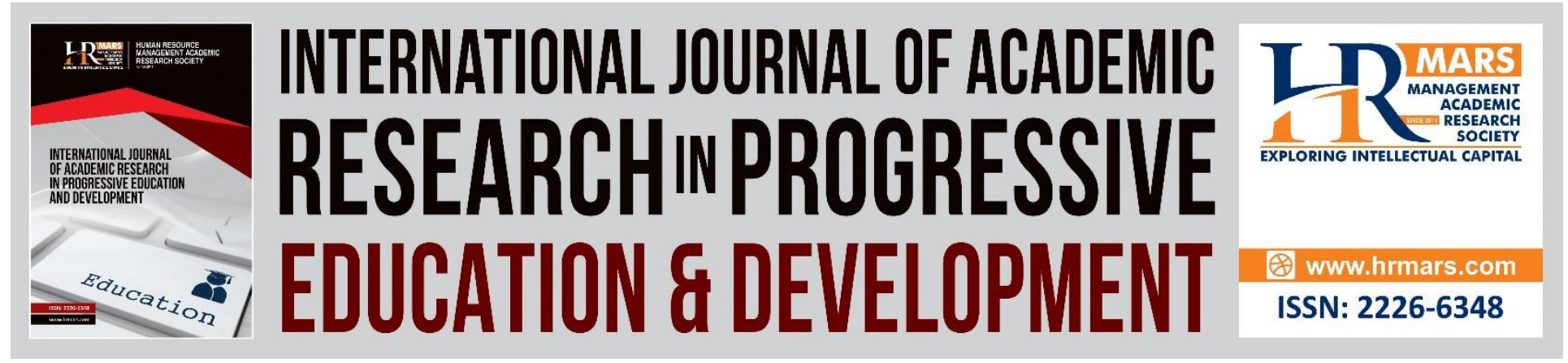

\title{
Big Data towards Decision-Making Culture in Organization
}

\author{
Saiful Farik Mat Yatin Ahmad Nasim Mohd Sidek, Hanis Zawani \\ Mobidin, Siti Nurul Atiqah Adam \\ Faculty of Information Management, Puncak Perdana Campus, UiTM Selangor, Malaysia \\ Email: farik@salam.uitm.edu.my, nasimsidek@gmail.com
}

\begin{abstract}
Big data is data sets that are so voluminous and complex that traditional dataprocessing application software is inadequate to deal with them. Big data challenges include capturing data, data storage, data analysis, search, sharing, transfer, visualization, querying, updating, information privacy and data source. There are five dimensions to big data known as Volume, Variety, Velocity and the recently added Veracity, Value and Variability. This article discusses the capabilities of organizational involved in the big data chain of information, influences the outcomes in making decision.
\end{abstract}

Keywords: Big Data, Decision Making, Information Management

\section{Introduction}

Big Data (BD), the new frontier has begun with large volume, complex and growing data generated by various distinct sources either human or machine. Nowadays, millions of data generated which nearly every aspect of modern society is impacted by these phenomena either management business or government. This new era has brought almost every organization driving in looking for ways to harness the power of BD to improve their predictive power in decision making. Elgendy and Elragal (2014) said BD is "closely related to BD Analytic which needed to create value of the data." The recent upsurge began with the special issues entitle "Big Data" published by Nature (National Science Foundation, 2011). After the BD initiative presented by Obama Administration in 2012, Garner listed BD in both the "Top 10 strategies Technology Trends for 2013" and "Top 10 critical Tech Trends for the Next Five Years" (Wang et. al., 2016).

\section{Definition of Terms}

Several terms been defined to focus on the scope of the discussion in this paper. Big Data reflect a vast amount of disordered data, collected by different types of business and state organization (Koscielniak and Puto, 2015). Big Data Analytics on the other hand is the process of examining large and varied data sets -- i.e., big data -- to uncover hidden patterns, unknown correlations, market trends; customer preferences and other useful information that can help 
DEVELOPMENT

Vol. 7, No. 3, July 2018, E-ISSN: 2226-6348 @ 2018 HRMARS

organizations make more-informed business decisions (Rouse, 2013). Decision making can be defined as the study of identifying and choosing alternatives based on the values and preferences of the decision maker (Fulop, 2001) and "strategic decision-making process" was defined as a non-routine decision process, usually with long-term consequences. (Hadelin and Allwood, 2002)

\section{The Idea of Big Data \\ Concepts of Big Data}

Koscielniak and Puto (2015) indicates that the concept of Big Data has evolved over the last several decades; in the literature, the most frequently adopted definition is the one by Douglas Laney who, in 2001, claimed that it is a vast amount of data generated very quickly and containing a large amount of content. In this sense, a National Science Foundation (2011) solicitation refers to Big Data as "large, diverse, complex, and distributed data sets generated from instruments, sensors, Internet transactions, emails, videos, and all other digital sources available today and in the future." In addition, the word big is not just about the size. Gobble (2013) states that "data is big because there is too much of it, because it is moving too fast, or because it is not structured in a usable way."

\section{Characteristics of Big Data}

Lycett (2013) indicated bigness of data refers to the increasing availability of data that provides the impetus for the use of data analytics. Several definitions of the concept currently exist with the considering the emerging nature of "Big Data" with 'Vs' to define 'big data'. Three pillars or words, which are volume, variety and velocity, are commonly being characterized as big data and highly discussed (e.g., Laney, 2001; Russom, 2011; McAfee and Brynjolfsson, 2012; Kwon and Sim, 2013; Lycett, 2013; Raghupathi, 2014):

- Volume defined as the amount of data, which is increasing significantly. The volume of big data may reach the level of terabytes or even petabytes, which is far beyond the conventional limits of megabytes or gigabytes. Ertemel (2015) estimated that by 2020 , the data created will be 50 times more than the amount of data in 2011.

- Variety refers to the many sources and types of data. There are structured data (e.g., numbers, dates), semi-structured data (e.g., XML documents), and unstructured data (e.g., videos) that firm are now dealing from within and outside the organization.

- Velocity indicates to the speed at which the data is created. This new dynamic characters of the data, has created a new craving for generating results in realtime. For example, in 2015, 100 hours of video were uploaded to YouTube every minute (Ertemel, 2015).

In addition to the three $\mathrm{V}$ 's, other dimensions of big data have also mentioned as complement features of big data (e.g., Dijks, 2012; Iview, 2012; White, 2012; Katal et. al., 2013; Fosso et. al., 2015):

- Value focuses on the importance of extracting economic benefits from Big Data.

- Veracity highlights the importance of quality of the data and the level of trust in various data sources. 
INTERNATIONAL JOURNAL OF ACADEMIC RESEARCH IN PROGRESSIVE EDUCATION AND DEVELOPMENT

Vol. 7, No. 3, July 2018, E-ISSN: 2226-6348 @ 2018 HRMARS

- Variability considers the inconsistencies of the data flow.

\section{Big Data Value Chain}

Janssen, Voort and Wahyudi (2017) suggested that as quoted, "the Big Data chains begins with collecting the data from the sources and ends when data-based decisions are taken. A Big Data chain consists of subsequent activities that can be distinguished analytically." The term 'chain' refers to the analytical view taken on the collaboration (Stank, Keller and Daugherty, 2001).

There are several steps for the Big Data process starting with data harvesting and end-up resulting in decision-making. There are some salient points about the steps among researchers. For example, Bizer et al., (2012) identify six (6) steps; data capturing, data storage, data searching, data sharing, data analysis and data visualization. Marx (2013) proposes five (5) steps; problem definition, data searching, data transformation, data entity resolution, answer the query/solve the problem. In contrast Chen and Liu (2014) only use three steps; data handling, data processes and data moving. An effective big data chain requires building capabilities and capacity for data management (Chen and Hsieh, 2014). The capabilities of each organizational involved in the big data chain of information, influences the outcomes. Thus the ability of organization and firms to collect, prepare and analyze big data might be different based on each entities capabilities.

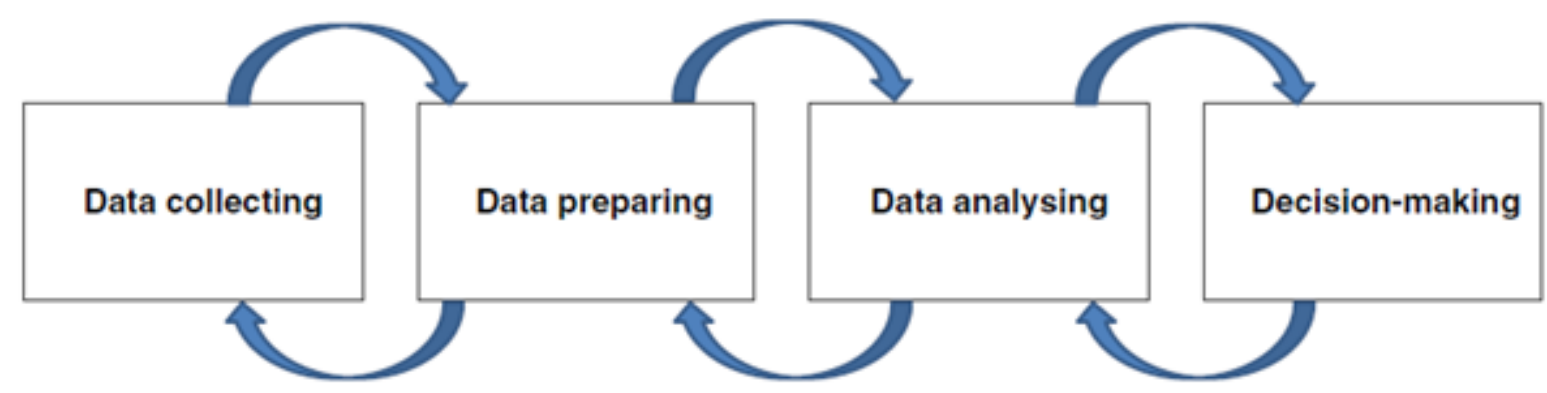

Figure 1: Steps and transfer points in the big data chain

Base on the Figure 1 above, the use of Big Data and Big Data Analytic was initially unplanned and dynamic in nature. At first the data was there, but nobody has any clear idea on how it could be used. Often but also debatable, there are four processes were connected and related which respectively data collecting, preparing, analyzing and finally tailored for decision making. The Big Data collection was often an ad-hoc process based on personal relationship, which incidentally required the making of agreements with other organizations. Next was to improve data quality that performed activities related to improving the data quality such data cleansing or enrichment and molding a data set in making it perfect data analytics. Once the data is ready, the data scientist will start analyzing the data to identified patterns, identifying trends and try to come out with prediction if possible if the data is adequate enough to calibrate the trend. The analysis will be prepared usually in various data visualizing format for use by stakeholders and decisionmakers. The head of the big data analytic usually known as the chief data scientist and his 
Vol. 7, No. 3, July 2018, E-ISSN: 2226-6348 @ 2018 HRMARS

or her team will present the results to the board or stakeholders. At later stages all of these output of the Big Data chains will be integrated in the operational processes (Janssen, Voort and Wahyudi, 2017).

Another example of value chain is based on Figure 2 below. The study about the decisionmaking, in general, exists in each procedure of Big Data, such as data acquisition/storage, data cleansing/integration, data analysis, data visualization and predicting by derived knowledge. Based on the paradigm of producing Big Data, the relationship between decision science and Big Data was shown by Figure 2.

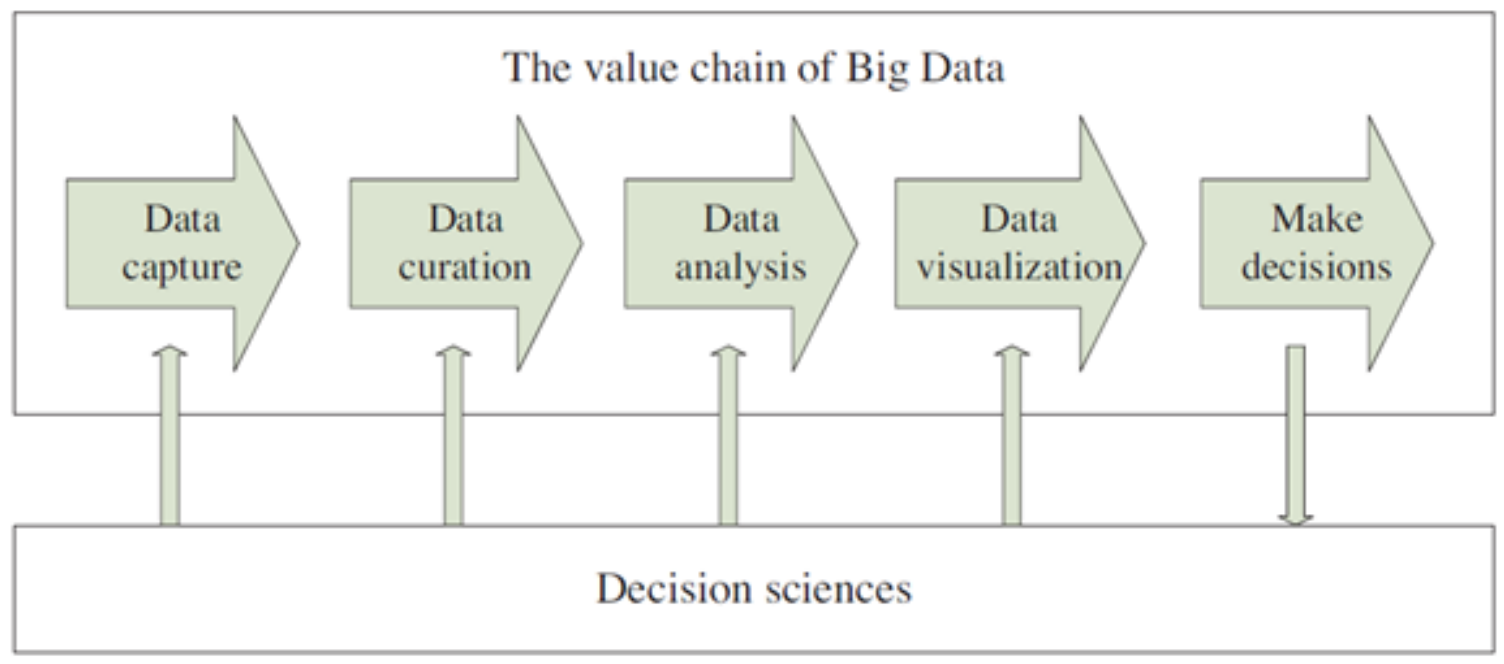

Figure 2: The relationship between Big Data and decision sciences

"Decision theory supports decisions in each phase of processing Big Data; the solutions of Big Data enrich the content and scope of decision sciences. In this sense, one can make more intelligent and felicitous decisions by utilizing better prediction. The first aspect focuses on the emerging techniques and technologies that are elaborately designed for processing Big Data based on decision sciences, whereas the second aspect concentrates on specific applications which process special data sets to support decision making in specific fields such as business and management" as quoted by (Wang et. al., 2016).

\section{Decision-Making Culture}

Snibbe and Markus (2005) stated that there is a social endorsement in independent cultural context that promote the values of uniqueness, self-reliance, self-expression, and autonomy. So, some future explanations for vary decision mode demand with cultural norms tangled with individualism or collectivism.

Muller, Spang and Ozcan (2009) in their studies has identified about twelve categories of cultural differences but they focus only into three (3) main categories which are: Team and Consensus Orientation. They clarify that it was included with consensus-orientation, individualism vs. team-orientation and also partnership collaboration. Secondly is the Organization that covers in leadership with or without authority, flexibility in executing work, confident appearance, structured working, and consequence-orientation. Finally, is Individualism that being such factors as significance of private life, identification with project 
Vol. 7, No. 3, July 2018, E-ISSN: 2226-6348 @ 2018 HRMARS

results, open-minded communication orientation and finally, solution and problemorientation.

Hofstede, Hofstede and Minkov (2010) express "culture as the collective programming of the mind that distinguishes the members of one group or category of people from another". Another four dimensions about culture according to Hofstede (2011) which are; Masculinity versus Femininity, as a societal and not an individual's representative and it is "refers to the distribution of values between genders". Individualism versus Collectivism, in an individual society, there is a desire that people see after themselves and associations between people are free; meanwhile in collectivist society, people are coordinates into solid, cohesive bunches, which may frequently include bigger family. Uncertainty Avoidance is a dimension that indicates the level of ease with unstructured situations and it is different from risk avoidance. It covers a cultures tolerance for doubt. Lastly, the Power Distance refers to the levels which less powerful committee of organizations accept and expect unequal power supplies. This dimension is measured from the followers and was not only from the perception of leaders.

Adam (2016) believes that the culture itself has influences on the development growth and the organization transformation at various levels. Nevertheless, the way the culture impact on the decision-making process is depends on different reasons. There is no much detail explanation of the relation between culture and decision-making process, but there is a prerequisite for an integrative research that clearly ponders the impact of the situation on the strategic decision-making procedure. The cultural differences need to be identifying in order to understand why there is the difference in any decision-making. Frank and Stephanie (2016), stated that there are cardinal issues across cultural which in the preliminaries, they considered need, mode and investments. In further point of "need", there are attention differences, information interpretation and motivational differences to be considered. The differences of culture probably may lead to different decision-making since the beginning. It is differing in culture interpretations on the same data whether it is chances or threats that finally the decision engaged to their interpretation. Alattar et al., (2016), stressed the point "mode" is referring to what or who is tangled in producing a given decision and how it made.

Frisk and Bannister (2017) simplified in their research according their literature review, there are differences in values and behavior of person from different national cultures and in order to improve organizational performance, the organizations were needed to have revolution in decision making culture.

\section{Suggestion}

Frisk and Bannister (2017) suggested in order having a successful decision making in organizations, there are suggestions to be considered;

- Moving from an individual perspective to a collaborative perspective;

- Moving from a culture of fast decision-making (something essential at the front line, but not useful for ICT investments) to a considered and systematic form of decision-making;

- The development of a common language that facilitated the future collaboration and understanding between managers with different roles, in different functional areas and at different levels; 
- Change from a dominant technical perspective to pluralistic value perspectives across levels in the organization and the transformation in modes of communication that accompanied this;

- A change from an individual value perspective to an organizational value perspective.

- The achievement of organizational learning by considering business problems in order to improve the decision-making.

Therefore, the differences of culture probably may lead to different decisionmaking since the beginning. The cultures must be accepted, and cross-cultural dialogues were followed in order to promote learning.

\section{Big Data Analytics}

Analytics in modern day business can be best defined as engaging in use of datastructured or unstructured, with formal analysis-statistical or machine learning, to arrive at learning that help in making better business decisions. The outcome of modern day analytics is more often than not a probabilistic outcome, in that analysis helps generate probabilities for various outcomes instead of suggesting one (1) deterministic outcome with certainly (Agrawal, 2014). As quoted again from (Agrawal, 2014), "Data is often generated by other organizations, by users on social media or provided by devices of the Internet of Things (IOT). The variety of data sources, the need to combine between organizations and departments to create a flow of activities organizational silos are locking the use of big data for decision making."

\section{The Speed of Big Data Analytics Technological Development}

"At a fundamental level, identifying patterns and compute/assign probabilities to different states is what Big Data Analytics (BDA) is about" (Agrawal, 2014) that some of the popular BDA analytical techniques are:

- Artificial Neural Networks for classification and prediction.

- Random Forest for classification.

- Support Vector Machine for classification.

- Bayesian Networks for creating probabilistic graphical model representing impact of interconnected nodes/ objects.

- Text Mining to perform sentiment analysis of unstructured text.

- Hidden Markov Models for speech, handwriting and gesture recognition.

Latest development in big data analytics has also popularized big data in visual analytics tools such as facial recognition, soft biometrics and other future potentials. New discoveries in any analytical techniques may change the way how a decision based on data will be made. As an example, new combination between sentiment analytics and visual analytics analysis might lead into some new discoveries in behavioral predictions such as in prison or police lockup. Latest development in this new technology may become faster than the capability or speed for human being to adapt to its changes. As mention by Bumblauskas et al., (2017) "As data sets become larger, the scope and 
scale of big data will constantly grow and evolve". This may create conflict in any data driven decision making with the evolution of the processes.

\section{Challenges Data In Driven Decision-Making}

Today's challenging world, the fast demand and accurate decision either short, medium or long run is the act or process deciding something especially with a group of people. A decision is a choice made from among available (explicit or implicit) alternatives, and choosing a course of action lies at the heart of decision making. Decision quality is a measure of rationality of this choice (Gonzales and Kasper, 1999).

\section{Highlighting Salient Points to Reduce Argument}

The used of big data in an organization will help it making accurate decision. In developing any organization strategic decision, it is important that evidentiary data with the support of analytics tools must be referenced to in supporting any organization's rationale for any decision-making. He, Wang, and Akula, (2017) opines "to better manage extracted knowledge from the big social media data and derive more business value, there is also a strong need for forward thinking companies to build Big Data analytics capabilities". The most common decision (Agrawal, 2014) help by analytics in a company are; Concept Development and Testing; Product Development and Feature Prioritization; Advertising Testing; Brand Strength; Preference and Perception; Customer Satisfaction and Loyalty; Marketing Mix Optimization; Pricing; Customer Segmentation; and Text Mining-Sentiment Analysis.

There are various opinions either conflicting or argumentations which need to be address during the decision-making process. As noted (Frisk, Bannister, and Bannister, 2017), "for them response time, response effectiveness, and the information and system needed to deal with the emergencies dominated. They were impatient with the processes and information demands that were deemed necessary by senior management, but which for them were are distraction". To reach for a conclusion in environments full with arguments, any strategic planners in an organization have abundance of data and its tools at their hand to support or analyze any salient points in their discussion.

\section{Balancing Act to Irrationality}

The most expert decision-makers in real situation often experience the decisionmaking process, not as a moment of choice based on a rational evaluation of various alternatives, but rather as spontaneous action taken in conjunction with the demands of the situation based on previous experience from similar situation (Hedelin, and Allwood, 2006). Based on this statement, even the best decision makers can be bias and irrational in making big decisions. This where big data can play its role in reducing bias and irrational decision based on facts rather than feeling either for fast big gains or long term strategic decision making. As "people lie, data doesn't", any contrary arguments will be based on evidence as any strategists will endeavor its journey in drafting, planning and deciding their organization future. Even on such subjective evaluation on quality of services as stated by He et al., (2017), "they were able to decompose user 
Vol. 7, No. 3, July 2018, E-ISSN: 2226-6348 @ 2018 HRMARS

reviews into five dimensions to measure hotel service quality, and the sentiment analysis results showed a high level of accuracy in capturing and measuring service quality dimensions". However, in the end it does not radically eliminated any irrationality in making any decision but it will just reduce the possibilities.

\section{Supporting Choices and Alternatives}

The term "strategic decision-making process" was defined as non-routine decision process, usually with long term consequences (Hedelin et al., 2006). Data driven decision is much similar concept Information Technology (IT) and strategic decision making. In making a decision assisted by technology, the decision-maker understands of the choice and alternatives are supported by IT or analytics from big data in the construction of the decision alternatives. A proven few studies by López Barbosa, Sánchez-Alonso and Sicilia-Urban (2015), have looked at what services generate more positive opinions and sentiment analysis is well suited to this task". It will also encourage transparency in decision making as stated by Massis and Massis, (2016), that capturing, analyzing and reporting decision based on data are indispensable to ensure a proper level of transparency". However, the main goal for computerized decision-support systems is to improve decisions quality. A prerequisite to this is that the senior executives really use computers (Gonzales and Kasper (1999). This is most common dilemma in today's office environment where senior level officials tend to leave anything regarding his or her computer to their secretary. The main challenge is to get the buy-in from senior executive to learn and utilizes this new technology for the organizations advantage.

\section{Assisting E-Government Stakeholders}

"The future of modern welfare state is subject to the successful digitization of public services and administration" (Taipale, 2013; Saxena and Kumar Sharma, 2016). It is vital for big data to produce in any e-government services to be utilized for the good of the country. "What are the limits or potential, of big data in the public sector?" (Desouza and Jacob, 2014, p. 3). The biggest question is how big data will help stakeholders in making decision and how data driven decision can be implied in the government services. "Challenges to the government vis-à-vis the analysis of Big Data in diverse context contingent upon several riders such as socio-economic indicators, internal and external security, politico-legal landscape and the stage of globalization" (Saxena and Kumar Sharma, 2016). They added that in the end, the particular governments need to identify its need and user requirement in applying big data for decision making. "Further it will encourage civic engagement in decision making. While on the one hand, government will be apprised of the concern of the individuals and businesses, at the same time, government will be in the position to benchmark its policies and programs against these expectations. This would contribute towards greater engagements and participation, and better policies might be formulated in the future". Either in the end, both the people and the government will benefit tremendously in making a people centric policy by using big data analytics in making decision. 
INTERNATIONAL JOURNAL OF ACADEMIC RESEARCH IN PROGRESSIVE EDUCATION AND DEVELOPMENT

Vol. 7, No. 3, July 2018, E-ISSN: 2226-6348 @ 2018 HRMARS

\section{Conclusion}

The changes that evolve in big data where it emerges with business analytics and becoming a powerful tool in modern days' business and administration. Besides all of the changes happened, the main principle is still in using data to make better highly informed and rational decision, "as it is often said that information is power, and because data contains information, as therefore data is capable of giving power where Analytics is the endeavor which makes it possible to realize the true power of data" (Agrawal, 2014). In the nutshell, Bender and Fish, (2000); (Hedelin et al., (2006), "the transformation of data into information adds meaning, understanding, relevance and purpose. The change from information to knowledge can occur through the mediation of personal application, values and beliefs". In the end, in a process of making a decision, data will only an added supplement and it will not supersede human values and beliefs in making decision.

\section{References}

Adam S. T. (2016). "Impacts of Culture on Strategic Decisions" Exploring Culture and Strategic Decision-Making Process in the Sudanese Context". Selected Works (Https://Works.Bepress.Com/Tarig-Adam/1/), 12

Agrawal, D. (2014). Analytics based decision making. Journal of Indian Business Research, 6(4), 332-340. https://doi.org/10.1108/JIBR-09-2014-0062

Alattar, L., Yates, J. F., Eby, D. W., Leblanc, D. J., \& Molnar, L. J. (2016). Understanding and Reducing Inconsistency in Seatbelt-Use Decisions: Findings from a Cardinal Decision Issue Perspective. Risk Analysis, 36(1), 83-97. https://doi.org/10.1111/risa.12419

Bizer, C., Boncz, P., Brodie, M. L., \& Erling, O. (2012). The meaningful use of big data: Four perspectives - Four challenges. SIGMOD Record, 40(4), 56-60. http://dx.doi.org/10. 1145/2094114.2094129.

Bumblauskas, D., Nold, H., Bumblauskas, P., Igou, A., Bumblauskas, D., \& Nold, H. (2017). Big data analytics: transforming data to action. Business Process Management Journal, vol. 23, issue 3 (2017) pp. 703-720. https://doi.org/10.1108/BPMJ-03-2016-0056

Chen, M., \& Liu, S. M. Y. (2014). Big data: A survey. Mobile Networks and Applications, 19(2), 171-209. Computing, Noida, India. IEEE. Retrieved from http://ieeexplore.ieee.org/xpls/abs all.jsp?arnumber=6612229

Dijcks, J.-P., (2012). Oracle: Big data for the enterprise. Oracle White Paper.

Elgendy, N., \& Elragal, A. (2014). Big Data Analytics: A Literature Review Paper. Advances in Data Mining. Applications and Theoretical Aspects, 8557, 214-227. https://doi.org/10.1007/9783-319-08976-8 16

Ertemel, A.V. (2015). Consumer insight as competitive advantage using big data and analytics. International Journal of Commerce \& Finance. 1 (1), 45-51. 
INTERNATIONAL JOURNAL OF ACADEMIC RESEARCH IN PROGRESSIVE EDUCATION AND DEVELOPMENT

Vol. 7, No. 3, July 2018, E-ISSN: 2226-6348 @ 2018 HRMARS

Frisk, J. E., \& Bannister, F. (2017). Improving the use of Analytics and Big Data by Changing the Decision- Making Culture- A Design Approach. Management Decision, 00-00. https://doi.org/10.1108/MD-07-2016-0460

Fülöp, J. (2001). Introduction to Decision Making Methods. Operations Research, 1-15. https://doi.org/10.1.1.86.6292

Fosso Wamba, S., Akter, S., Edwards, A., Chopin, G., \& Gnanzou, D. (2015). How “big data” can make big impact: Findings from a systematic review and a longitudinal case study. International Journal of Production Economics, 165, 234-246. https://doi.org/10.1016/j.ijpe.2014.12.031

Ghasemaghaei, M., Ebrahimi, S., \& Hassanein, K. (2017). Data analytics competency for improving firm decision making performance. The Journal of Strategic Information Systems, (March), 0-1. https://doi.org/10.1016/i.jsis.2017.10.001

Gobble, M. M. (2013). Big Data: The Next Big Thing in Innovation. Research Technology Management, 56(1), 64-66. https://doi.org/10.5437/08956308X5601005

He, W., Wang, F., \& Akula, V. (2017). Journal of Knowledge Management, Vol. 21 Issue: 2, pp.275294. https://doi.org/10.1108/JKM-07-2015-0296

Hedelin, L., Allwood, C. M., Hedelin, L., \& Allwood, C. M. (2006). IT and strategic decision-making IT and strategic decision making. https://doi.org/10.1108/02635570210421318

Hofstede, G. (2011). Dimensionalizing cultures: The Hofstede model in context. Online Readings in Psychology and Culture, 2 (1). Retrieved from dx.doi.org/10.9707/2307-0919.1014.

Hofstede, G., Hofstede, G. J., \& Minkov, M. (2010). Cultures and Organizations: Software of the Mind, Third Edition. McGraw-Hill Education; $3^{\text {rd }}$. edition (p. 576). https://doi.org/10.2307/2393257

Iview, I.D.C., (2012). The Digital Universe in 2020: Bag Data. Bigger Digital Shadows, and Biggest Growth in the Far East. IDC iView: IDC Analyze the future, 1-16.

Janssen, M., van der Voort, H., \& Wahyudi, A. (2017). Factors influencing big data decision-making quality. Journal of Business Research, 70, 338-345. https://doi.org/10.1016/i.jbusres.2016.08.007.

Katal, A., Wazid, M., \& Goudar, R. H. (2013). Big data: Issues, challenges, tools and Good practices. In 2013 6th International Conference on Contemporary Computing, IC3 2013 (pp. 404-409). https://doi.org/10.1109/IC3.2013.6612229 
INTERNATIONAL JOURNAL OF ACADEMIC RESEARCH IN PROGRESSIVE EDUCATION AND DEVELOPMENT

Vol. 7, No. 3, July 2018, E-ISSN: 2226-6348 @ 2018 HRMARS

Kościelniak, H., \& Puto, A. (2015). BIG DATA in Decision Making Processes of Enterprises. Procedia Computer Science, 65(ICCMIT), 1052-1058. https://doi.org/10.1016/i.procs.2015.09.053

Kwon, O., Sim, J.M., (2013). Effects of data set features on the performances of classification algorithms. Expert Syst. Appl. 40 (5), 1847-1857.

Laney, D. (2001). META Delta. Application Delivery Strategies, 949(February 2001), 4. https://doi.org/10.1016/j.infsof.2008.09.005

López Barbosa, R. R., Sánchez-Alonso, S., \& Sicilia-Urban, M. A. (2015). Evaluating hotels rating prediction based on sentiment analysis services. Aslib Journal of Information Management, 67(4), 392-407. https://doi.org/10.1108/AJIM-01-2015-0004

Lycett, M. (2013). "Datafication": Making sense of (big) data in a complex world. European Journal of Information Systems, 22(4), 381-386. https://doi.org/10.1057/ejis.2013.10

Marx, V. (2013). Biology: The big challenges of big data. Nature, 498(7453), 255-260.

Massis, B., \& Massis, B. (2016). WHAT' S NEW IN LIBRARIES Data-driven decision-making in the library. https://doi.org/10.1108/NLW-10-2015-0081

McAfee, A., Brynjolfsson, E., (2012). Big data: the management revolution. Harvard Bussiness Review. 90, 60-69.

Müller, R., Spang, K., \& Ozcan, S. (2009). Cultural differences in decision making in project teams. International Journal of Managing Projects in Business, 2(1), 70-93. https://doi.org/10.1108/17538370910930527

National Science Foundation. (2011). Core Techniques and Technologies for Advancing Big Data Science \& Engineering, 1-17.

Raghupathi, W., Raghupathi, V., (2014). Big data analytics in healthcare: promise and potential. Health Inform. Sci. Syst. 2 (1), 3.

Rouse, M., (2013). Big data analytics. Retrieved from searchbusinessanalytic.techtarget.com/definition/big-data-analytics.

Russom, P. (2011). Big data analytics. TDWI Best Practices Report, Fourth Quarter, 6. Retrieved from ftp://129.35.224.12/software/tw/Defining Big Data through 3V v.pdf

Saxena, S., \& Kumar Sharma, S. (2016). Integrating Big Data in "e-Oman": opportunities and challenges. Info, 18(5), 79-97. https://doi.org/10.1108/info-04-2016-0016 
INTERNATIONAL JOURNAL OF ACADEMIC RESEARCH IN PROGRESSIVE EDUCATION AND

DEVELOPMENT

Vol. 7, No. 3, July 2018, E-ISSN: 2226-6348 @ 2018 HRMARS

Snibbe, A. C., \& Markus, H. R. (2005). You Can't Always Get What You Want: Educational Attainment, Agency, and Choice. Journal of Personality and Social Psychology, 88(4), 703720. https://doi.org/10.1037/0022-3514.88.4.703

Stank, T. P., Keller, S. B., \& Daugherty, P. J. (2001). Supply chain collaboration and logistical service performance. Journal of Business Logistics, 22(1), 29-48.

Trompenaars, F., \& Hampden-Turner, C. (1993). Riding the waves of culture: Understanding cultural diversity in business. Long Range Planning, 26(5), 153. https://doi.org/10.1016/0024-6301(93)90118-Y

Wang, H., Xu, Z., Fujita, H., \& Liu, S. (2016). Towards felicitous decision making: An overview on challenges and trends of Big Data. Information Sciences, 367-368, 747-765. https://doi.org/10.1016/i.ins.2016.07.007

White, M., (2012). Digital workplaces: Vision and reality. Bus. Inform. Rev. 29 (4), 205-214.

Yates, J. F., \& de Oliveira, S. (2016). Culture and decision making. Organizational Behavior and Human Decision Processes, 136, 1-2. https://doi.org/10.1016/i.obhdp.2016.05.003 